\title{
Does Rising Inequality Delay Marriage? Evidence from India
}

\author{
A. V. Chari* \\ Annemie Maertens ${ }^{\dagger}$ \\ Sinduja Srinivasan $\ddagger$
}

November 2016

\begin{abstract}
Top incomes in India have been rising sharply, relative to incomes in the rest of the distribution. In this chapter, we show that this phenomenon has resulted in a delay in female marriage. Our analysis takes advantage of variation in earnings distributions across narrowly defined marriage markets. We examine a number of hypotheses, and conclude that the pattern of results suggests a mechanism in which increases in top male incomes prolong the duration of marital search on the part of women.
\end{abstract}

\section{Introduction}

The age at which women get married is important because it matters for fertility, and the consequent trade-off between quality and quantity. In poor countries, where a large

\footnotetext{
*University of Sussex. Email: a.chari@sussex.ac.uk

${ }^{\dagger}$ University of Sussex. Email: a.maertens@sussex.ac.uk

${ }^{\ddagger}$ Economic Council for Latin America and the Caribbean (ECLAC). Acknowledgements: We are grateful to Andy Newell, Vikram Pathania, seminar participants at the University of Sussex, PACDEV, the PRGS Brown Bag at RAND, APPAM International Conference, and to the CeMENT workshop participants (Adriana Kugler, Laura Schechter, S. Anukriti, Rachel Heath, Melanie Khamis and Shing-Yi Wang) for comments and feedback. Any remaining errors are our own.
} 
proportion of girls are married in their teens, early marriage has also been found to predict a number of adverse outcomes, including miscarriages, multiple unwanted pregnancies, domestic violence, depression and even increased HIV risk (Bruce 2003, Clark 2004, Nour 2006, Raj et al 2009, Santhya et al 2010). It is encouraging, therefore, that the last few decades have witnessed a secular upward trend in the age at marriage across developing countries (Jensen and Thornton 2003). This phenomenon is usually attributed to factors such as improved work opportunities and the returns to education for women, and better enforcement of legal age minimums.

A different set of explanations relate to the structural features of the marriage market itself. Interestingly, although the standard model of marriage formation propounded by Becker (1974) is silent about when women get married, later extensions that incorporate the realistic frictions involved in meeting potential partners (Burdett and Cole 1995, Smith 1995) have a natural implication in terms of the average search duration that women will experience before agreeing to a match, and therefore the average age at marriage. In this search/match theoretic framework, search duration depends on the frequency of meetings (which depends on the intensity of search as well as on the relative numbers of men and women), and the distribution of marriage-market relevant characteristics among potential partners. The first of these factors has received considerable attention in the empirical literature (e.g. Schoen 1983, Lichter et al 1992, Angrist 2002, Attane 2006, RiosRull et al 2013) and is referred to as the marriage squeeze hypothesis. However, the second has received relatively little attention.

In this chapter, we examine how the income distribution of marriageable males affects female marital search duration and the age at marriage in India. We focus on income distribution for three reasons. First, income is arguably the most important non-caste male attribute of relevance in the marriage market; second, the income distribution has been changing rapidly in India in the last few decades - while average incomes have increased, these gains have been disproportionately been captured by the highest earners 
(Banerjee and Piketty 2005) - and the effects of these changes on marriage decisions are as yet unknown; third, because rates of female labor force participation were quite low over the study period, changes in the income distribution largely work through one side of the marriage market, which makes it easier to predict their effects as well as to disentangle them empirically from factors that may affect women directly.

In a simple model of marital search, an increase in the income of the average male has an ambiguous effect on search duration (and hence female age at marriage), whereas an increase in income inequality of the kind that India has experienced should be expected to increase search duration - this is therefore a surprising beneficial effect of increasing income inequality. The basic intuition behind this hypothesis is that an increase in top incomes among men encourages the average woman to wait for offers from high-earning candidates, thereby increasing her expected search duration. Loughran (2002) finds empirical support for this hypothesis in the context of the United States, estimating that increases in male wage inequality may have accounted for $7-18 \%$ percent of the decline in marriage rates for women between 1970 and 1990, an effect at least as large as that of factors such as increasing female labor force participation and access to birth control. In contexts in which dowry (or groom-price) is practiced (as in India), however, an important countervailing force applies, because the income increase at the top of the distribution gets priced in the form of dowry, i.e. men whose incomes have increased will demand more dowry, which dampens the effect of their increased income. Whether increasing income inequality has a meaningful impact on age at marriage in such a setting is therefore an empirical question.

We examine this question by utilizing a rich source of household data that has unusually comprehensive information on individual income that includes income from selfemployment and imputed income from participation in household farm and non-farm businesses: This is particularly important for our purpose because a significant proportion of income (especially in rural settings) is derived from non-wage sources. The analy- 
sis faces two related empirical challenges. First, it is difficult to isolate quasi-experimental variation in the income distribution, in order to obtain its causal effect on outcomes of interest. Second, it is difficult to determine the underlying mechanism by which changes in the income distribution affect outcomes. We attempt to address these challenges as follows: We utilize the fact that marriage markets in India are segmented by caste and geography, which implies that we can examine the effect of income distribution within a particular marriage market while controlling for confounding factors that apply at levels broader than the marriage market by means of state and caste fixed effects. Because marriage markets are quite narrowly defined, this strategy credibly isolates effects that arise via the marriage market. A more stringent test of the mechanism is possible, because conditional on the male income distribution in a particular marriage market, marital outcomes in that market should not be affected by changes in the male income distribution in other marriage markets. This indeed turns out to be the case, and provides a strong confirmation that we are picking up effects that work via the marriage market, rather than through other markets (e.g. the labor market).

Overall, the results indicate that rising male income inequality has a causal effect on the female age at marriage. The effects of changes in the male income distribution are however nuanced: Specifically, female marriage rates (and the age at marriage) decline in response to increases in top male incomes, but are unresponsive to changes in the rest of the male income distribution. We also find marked effects on women's educational attainment (in terms of years of schooling, as well as high school and college completion rates). The results are robust to the inclusion of a wide range of controls including measures of female income distribution, observable female characteristics and marriagemarket relevant factors such as the sex ratio. We also find that the effects are not stronger for uneducated women, indicating that the increased age at marriage is not a consequence of a decision to seek more education.

The chapter proceeds as follows. Section 2 outlines a simple marital search framework 
which provides intuition for the empirical analysis. Section 3 describes the data used in the main analysis. Section 4 describes the empirical strategy and the results, and Section 5 concludes.

\section{A model of marriage market search}

We sketch the outline of a model of marital search that suggests some predictions that can be tested in the data. The basic intuition can be summarized as follows: An increase in income at the top of the distribution makes high-earning men relatively more attractive candidates than before, and makes women reluctant to accept proposals from lowerearning candidates. Because proposals do not all arrive at once, this tends to increase the duration of time that a woman remains unmarried. The search-theoretic approach, which has been frequently used to model the process of match formation in marriage markets (e.g. Becker, Landes and Michael, 1977; Boulier and Rosenzweig, 1984; Bergstrom and Bagnoli, 1993), offers a natural way to formalize this hypothesis.

The setup of the model is analogous to that of a model of labor search: An infinitelylived, risk-neutral woman sequentially samples marriage offers from a known distribution of offers, before finally accepting an offer (Maertens (2013) finds that women in rural Andhra Pradesh and Maharashtra sample an average of five prospective candidates). As in Loughran (2002), we assume that women prefer high-earning males over low-earnings males and that this is the only dimension of groom heterogeneity, so that the male earnings distribution characterizes the distribution of offers.

We assume that the woman receives exactly one offer in each period and that this offer is an independent and random draw from the male earnings distribution. The earnings associated with this offer is denoted by $x$. The woman may either accept or reject this proposal. If she chooses to reject it, she will have to wait one more period, during which she will receive a utility of $c$, which is the per-period utility from remaining single (and 
which may be negative for some women).

The form of the solution to this optimization problem is known to be the following: There is a reservation earnings level, denoted by $R$, above which the woman will accept any offer, and below which she will reject any offer. Associated with $R$, one can define the per-period probability of "escape" from the marriage market, i.e., the probability of getting married, $q$ :

$$
q=P(x>R)
$$

Lower values of $q$ imply greater search duration (in expectation), or equivalently, higher age at marriage. The expected number of periods of search before an offer is accepted can be shown to be $1 / q .^{1}$

It can be shown in this model that a mean-preserving spread in the male earning distribution unambiguously increases the reservation level $R$. The effect on search duration is ambiguous, but it is likely that for most values of $R$, the net effect on search duration is positive (Burdett and Ondrich 1985). We refer the interested reader to the proofs in Mortensen (1986) and Loughran (2002).

We are unlikely, however, to observe mean-preserving spreads in the data. The available evidence indicates that for a number of English-speaking countries as well as India and China, recent increases in income inequality are largely being driven by increases in income for people in the upper tails of the income distribution (Atkinson, Piketty and Saez 2011). Banerjee and Piketty (2005) use income tax data to show that incomes of the top $1 \%$ in India increased by $50 \%$ in the 1990 s, and that their share of total income nearly doubled. In the empirical analysis, we will accordingly separate out the impact of increases in upper-tail incomes (relative to median incomes) from the impact of reductions in lower-tail incomes.

While analytical proofs are difficult, it is possible to intuitively predict the direction of

${ }^{1}$ Formally, the time to marriage follows a geometric distribution, and the average waiting time of such a process is the reciprocal of the per-period probability of success. 
impact in these cases. Consider an increase in income at the 90th percentile (say), relative to the median income. For women with reservation levels below the 90th percentile (this includes the majority of women), this would increase the value of rejecting an offer equal to $R$. This would result in an increase in $R$ and (most likely) an increase in search duration. However, a reduction in income at the 10th percentile (say) relative to median incomes, would have no effect on reservation levels and search durations for women whose initial reservation levels were above the 10th percentile (this likely includes the majority of women). These asymmetric predictions can be tested in the data.

A complication that is not addressed in the one-sided search model is that the set of candidates that would potentially be willing to make offers to a given woman is determined in equilibrium, and will depend on the search strategies of both men and women. In general, the impact of an increase in male income inequality may not be the same for all women, because the pool of candidates that a woman would potentially receive offers from would depend on her own characteristics relative to other women. Because the data do not contain any information on the pre-marital characteristics of women (especially the socio-economic circumstances of their natal households), we are unable to test for such heterogeneous effects. We have therefore chosen to model the search process on the part of a woman, while abstracting from the search behavior on the part of men, but it should be understood that the empirical relationship between income inequality and female age at marriage captures the average effect on all women in equilibrium.

Second, we consider how these conclusions are affected once we allow for dowry transfers. The institution of dowry (an in-kind/cash transfer from the bride's household to the groom's household at the time of marriage) is still remarkably prevalent in India. Dowry is commonly thought of as representing a compensating transfer that is increasing in the productive characteristics of the groom (e.g. Rao 1993). In a marriage market where dowry transfers are allowed, it is plausible that an increase in their incomes should increase the dowry payments demanded by high-earning men - this would partially offset 
the increase in their desirability as grooms. As a result, an increase in upper-tail incomes can be expected have a smaller impact on marital search durations in a marriage market with dowry transfers.

A second institutional feature not captured in the model is that women in India experience a significant amount of social pressure to get married early, and being unmarried invites social stigma. Caldwell et al (1983) note that "... a major control over the age at marriage of women is provided by the fact that many families feel deep disquiet and guilt over the presence of an unmarried menstruating daughter in the household..." In terms of the model, this could be accommodated by allowing the utility from remaining single, $c$, to decline (or become more negative) with search duration. It is intuitive that in this environment, the impact of an increase in income inequality on search duration will be smaller than in an environment in which $c$ is (relatively) fixed.

\section{Data}

The analysis makes use of the India Human Development Survey (IHDS), conducted in 2005. The IHDS is a nationally representative survey of 41,554 rural and urban Indian households in all twenty-eight states and five union territories. ${ }^{2}$ The IHDS administered household, school, village, and medical facility surveys, collecting poverty, health, employment, economic, and social data.

Defining the analysis sample: The analysis uses two overlapping samples of women. The first sample is derived from the household roster, which provides the age and marital status of each household member. The outcome of interest for this sample is their current marital status. We restrict attention to women of "marriageable" age, defined to be those between the ages of 14 and 30 (nearly all women in India are married by the age of 30). We will refer to this as the "full sample", which consists of 27,454 women. The second ${ }^{2}$ Lakshwadeep and the Andaman and Nicobar Islands were excluded. 
sample consists of ever-married women (one such woman was randomly chosen from each surveyed household), who were administered a detailed questionnaire. The evermarried women were interviewed about their marriage and birth histories, health beliefs and educational attainment. The main outcome of interest for this sample is their reported age at marriage. Once again, we restrict attention to those between the ages of 14 and 30. In addition, to address the issue that some of the women may have married many years ago (when the extent of income inequality in the marriage market was perhaps very different), we further restrict the sample to only include women who were married in the last two years. We refer to this sample as the "ever-married sample", which consists of 703 women.

\section{[Table 1 here]}

Table 1 presents descriptive statistics for the two samples of women. It is noteworthy that only a tiny fraction (4\%) of ever-married women are currently attending school, consistent with the observation that women typically drop out of school once they are married (if they have not already dropped out earlier). In the ever-married sample, the average age at marriage is 20.12 and the average educational attainment is 7.84 years. As a point of comparison, the average age and educational attainment of women who got married in 1987 were 17.23 and 3.70 respectively. $^{3}$

Defining the marriage market: As reported by Banerjee et al (2010) caste preference is extremely strong in Indian marriage markets, even in urban settings. About $95 \%$ of women in our ever-married sample reported marrying within their caste group. The households in our sample are categorized into five caste groups: Brahmins (6.86\%), Other high caste (20.16\%), Scheduled Castes (SC) (23.66\%), Scheduled Tribes (ST) (7.44\%) and Other Backward Classes (OBC) $(41.88 \%){ }^{4}$

\footnotetext{
${ }^{3}$ These were calculated by looking at ever-married women in the data who got married in 1987.

${ }^{4} \mathrm{SC}, \mathrm{ST}$ and OBC are official categories that are linked to various governmental quotas and reservations. The categorization we are using represents an admittedly high level of grouping: In actual fact, marriage markets are much more narrowly defined, with literally thousands of endogamous groups (known as
} 
Due to ethnic and linguistic differences between the states of India, the boundaries of a state form a second natural boundary for the marriage market. Partly as a result, the marital household is typically situated in close proximity to the woman's natal household: Nearly $90 \%$ of the women in the ever-married sample report that they live within 5 hours traveling distance of their families.

We now define the marriage market of a woman of "marriageable age" to include all unmarried men between the ages 18 of 35 , who belong to the same caste and state as the woman, and who are not currently enrolled in school. This gives rise to a set of 152 distinct marriage markets.

Constructing the distribution of earnings: The IHDS elicited detailed information on the employment, occupation, and earnings of individuals in the household, including the annual earnings of individuals from employment outside the home, the net income the household received from farm and business activities, and the contribution of each individual (in terms of days worked) to that farm or business. We use these data to construct a comprehensive measure of annual individual earnings, which accounts for earnings from paid employment for work done outside the home and the individual's share of net income from household farm and business ventures. To obtain this share, we assign household farm and business income to each household member in proportion to the number of days the individual spent on that activity during the year (relative to the total number of days household members devoted to the activity).

\section{[Table 2 here]}

Table 2 presents descriptive statistics on the earnings distribution for each caste group. The caste system is associated with an economic hierarchy (with Brahmins at the top), as can be seen from comparing the mean earnings of different castes (in fact, the earnings distributions for higher castes appear to first-order stochastically dominate the earnings becomes an issue in terms of being able to estimate earnings distributions for each marriage market. 
distributions for lower castes). The sample is evenly distributed between castes, with each caste associated with approximately 30 marriage markets in the data. There are 152 marriage markets in total, distributed across 33 states (an average of 5.5 marriage markets per state).

\section{Analysis}

\subsection{Effect of income inequality on marriage rates}

We begin by estimating the effect of income inequality on marriage rates. The baseline specification utilizes variation in income distributions (and hence income inequality) along caste and geographic dimensions, while controlling for unobserved caste- and region-specific factors (such as marital norms) by the inclusion of caste and state fixed effects. The following linear probability regression specification is used:

$$
y_{\text {iacs }}=\alpha+\beta_{1}\left(e_{c s}^{90}-e_{c s}^{50}\right)+\beta_{2}\left(e_{c s}^{50}-e_{c s}^{10}\right)+\beta_{3} e_{c s}^{50}+\eta_{a}+\eta_{c}+\eta_{s}+u_{i a c s}
$$

where $y_{\text {iacs }}$ is a dummy for whether woman $i$ of age $a$ belonging to caste $c$ and residing in state $s$ is married; $e_{c s}^{10}, e_{c s}^{50}$ and $e_{c s}^{90}$ denote the 10th, 50th and 90th percentiles respectively of the male income distribution in caste $c$ in state $s ; \eta_{a}, \eta_{c}$ and $\eta_{s}$ are age, caste and state fixed effects respectively, and $u_{i c s}$ is an error term. As before, the coefficients of interest are $\beta_{1}$ and $\beta_{2}$, which capture the effect of increases in upper-tail and lower-tail inequality, respectively. The regression sample includes all women of marriageable age, i.e. those between the ages of 14 and 30. The standard errors are corrected by clustering at the marriage market level.

[Table 3 here]

Column 1 of Table 3 reports the results from the baseline specification. In Column 
2, we examine whether the results are robust to controlling for an urban/rural indicator and the sex ratio (the ratio of marriageable males to females in the market); the latter is an important predictor of marriage rates that may be affected by changes in the income distribution. We find that income inequality has a robust effect on marriage rates. A 10,000 rupee increase in upper-tail earnings inequality (representing a roughly $24 \%$ increase over the average level of upper tail inequality) lowers the probability of getting married (on average) by 0.8-1.1 percentage points. Increases in lower tail inequality have smaller and statistically insignificant effects on the marriage propensity. It should be noted that the coefficients on the lower tail measures are also economically insignificant because lower tail inequality is much smaller on average than upper tail inequality: A 10,000 rupee increase amounts to $74 \%$ and $322 \%$ increases, respectively, in $\left(e_{c s}^{50}-e_{c s}^{10}\right)$ and $\left.\left(e_{c s}^{30}-e_{c s}^{10}\right)\right)$. Overall, the results in Columns 1 and 2 are consistent with the predictions of the model of marital search outlined in Section 2. In Column 3, we include controls for male earnings distribution in other marriage markets (i.e. not the one the woman is located in): Specifically we control for the earnings distribution measures averaged over all other caste groups in the woman's state, as well as the earnings distribution measures averaged over marriage markets in the same caste group as the woman but located in other states. We find that the effect of earnings inequality in the woman's own marriage market remains robust to the inclusion of these measures; interestingly, her decision does not appear to be affected by male earnings distributions in other marriage markets. This result provides a strong confirmation that the mechanism underlying the observed effect runs through the marriage market.

As a further check on the causal interpretation of the results, we test whether there are any systematic differences between women situated in high- and low-inequality marriage markets. For the test to be meaningful, we need to compare characteristics that are pre-determined with respect to the marriage market, i.e. they cannot themselves be outcomes of the marriage market decision. Natal household characteristics (e.g. mother's 
and father's education) are potentially suitable for this test, but the practice of patrilocality (whereby the bride moves into the groom's household after marriage) implies that we do not observe married women in their natal households. We have available, however, two observable characteristics of women that are arguably pre-determined in the sense described above: Height and age at menarche. These characteristics also have the benefit of being important predictors of the age at marriage: Height matters directly on the marriage market, in addition to being a good proxy for socio-economic status; and menarche usually triggers marital search. We utilize the same regression specification as before, but restrict the sample to ever-married women (because height and age at menarche are only observed for this sample). Table 4 presents the results. We find that neither of these pre-determined characteristics has a statistically significant correlation with the measures of income inequality, which further strengthens the causal interpretation of the results in Table 3.

The previous analysis established that an increase in male income inequality reduces marriage rates for women. To estimate the average implied increase in the age at marriage, we again turn to the ever-married sample for whom we have information on age at marriage. The regression specification is as follows:

$$
\text { Ageatmarriage }_{i c s}=\alpha+\beta_{1}\left(e_{c s}^{90}-e_{c s}^{50}\right)+\beta_{2}\left(e_{c s}^{50}-e_{c s}^{10}\right)+\beta_{3} e_{c s}^{50}+\eta_{c}+\eta_{s}+u_{\text {iacs }}
$$

where Ageatmarriage $e_{i c s}$ denotes the age at marriage of woman $i$ belonging to caste $c$ and residing in state $s$. Because this is a sample of married women, sample selection is an issue: In particular, younger women may be over-represented in low-inequality markets (relative to high inequality markets). This implies that the woman's current age is a "bad control", in the terminology of Angrist and Pischke (2008). Accordingly the specification above does not include controls for the woman's age.

[Table 5 here] 
Column 1 of Table 5 reports the results. A 10,000 rupee increase in upper tail inequality implies an increase in average age at marriage of 0.18 years. A second way to estimate the extent of delay in marriage, which does not entail the sample selection issue discussed above, is to estimate a duration model that uses the information on the (right-censored) survival times of unmarried women. To do so, we model survival time (i.e. time-tomarriage) as follows:

$$
\ln \left(T_{i c s}\right)=\alpha+\beta_{1}\left(e_{c s}^{90}-e_{c s}^{50}\right)+\beta_{2}\left(e_{c s}^{50}-e_{c s}^{10}\right)+\beta_{3} e_{c s}^{50}+\eta_{c}+\eta_{s}+u_{i c s}
$$

where $T_{i c s}$ is the (latent) survival time of woman $i$ belonging to caste $c$ and residing in state $s$. The error $u_{i c s}$ is assumed to be distributed according to an extreme value distribution. ${ }^{5}$ The model is estimated by maximum likelihood in order to take into account the censored observations for which marriage has not yet occurred. In this specification, the $\beta$ coefficients measure the proportionate effect on survival time of unit changes in the earnings measures.

The results are reported in Column 2 of Table 5, and indicate that a 10,000 rupee change in upper tail inequality would increase survival time by 1.6 percent. Because the average age at marriage in our sample is 20.12, this implies a delay in marriage of 0.32 years, a larger effect than obtained using the regression in Eqn (3).

We have interpreted our results through the lens of a marital search model. An alternative hypothesis is that an increase in top male incomes may simply be correlated with (i.e. acting as a proxy for) an increase in the returns to education, which may cause some women to stay in school longer and thereby postpone their marriage. This hypothesis can be directly tested by controlling for the returns to education, in the form of average earnings of women who have completed different levels of education. We will do so by including the (marriage-market specific) average female earnings for four levels of edbe thought of as a Proportional Hazards (PH) model or as an Accelerated Failure Time (AFT) model. 
ucational attainment: (i) Fewer than 6 years of education, (ii) Between 6 and 10 years of education, (iii) Between 10 and 12 years of education, and (iv) More than 12 years of education. An indirect set of tests is also possible: Differently from the marital search hypothesis, the returns to schooling hypothesis implies that an increase in male income inequality should not delay marriage for (i) Women who are no longer attending school, and (ii) Women who never attended school, and thus have zero years of education (this is a sizeable proportion of the sample of women). We can test these implications in the data. A benefit to implementing these indirect tests is that they also allow us to check whether the results are simply due to the male income variables being correlated with unobserved tastes for education among women.

\section{[Table 6 here]}

We implements these three tests in Table 6. In Column 1, we estimate the baseline regression model, but this time we control for the average female earnings variables described above. The coefficients on the male income variables remain virtually unchanged, however, when we do so, indicating that the latter are not very strongly correlated with female earnings. This is not particularly surprising, because women in India have generally participated in very different income-generating activities than men. In Columns 2 and 3, we re-estimate the baseline regression model splitting the sample into those who are still attending school (Column 2) and those who are not (Column 3). Both sets of women delay marriage in response to greater upper-tail inequality, indicating that women are not postponing marriage in order to obtain more education. In Columns 4 and 5, we split the sample into those who have zero years of education and those who have at least one year of education. The two sets of women respond almost identically to increases in upper-tail inequality. Together, these tests confirm that the estimated effects of top male incomes on female marriage are not simply picking up the effect of higher returns to female education or unobserved tastes for education. 


\subsection{Effect of income inequality on female education}

We have seen that the observed effect of income inequality on marriage rates does not obtain via an increased demand for education. Nonetheless, income inequality may affect educational attainment via the former's effect on marriage. Because schooling is typically discontinued after marriage ( $96 \%$ of the ever-married women in our sample are no longer in school), an important implication of increasing income inequality is that by delaying marriage, it may result in women staying in school longer and obtaining more education. To test this hypothesis, we begin by examining the effect of income inequality on the probability of current school attendance for the full sample. The results, reported in Column 1 of Table 7, are consistent with the estimates obtained for marriage propensities: A unit increase in upper tail inequality increases the probability that the woman is currently attending school by 0.9 percentage points.

\section{[Table 7 here]}

Next, we turn to the ever-married sample, restricting attention to those who are no longer in school, and examine the effect of income inequality on their completed years of schooling. The results, reported in Column 2 of Table 7, indicate that a 10,000 rupee increase in upper tail inequality increases years of schooling by 0.44 years. To account for the sample selection inherent in the ever-married sample, in Column 3, we estimate a duration model as in Section 5.2, where the dependent variable is completed years of schooling. The duration model estimates indicate that a 10,000 rupee increase in uppertail inequality should increase completed years of schooling by $2.4 \%$ - this amounts to approximately 0.18 extra years of schooling, a smaller estimate than that obtained in Column 2.

We can refine the analysis further by observing that the marital search hypothesis implies that higher inequality should increase educational attainment only to the extent that prolonged search extends the woman's attendance in school. Because women would nor- 
mally be in secondary school by the time they reach marriageable age, we would expect that an increase in income inequality would only affect rates of completion of secondary schooling (and above), but should not have an effect on the rate of completion of lower levels of schooling. In Table 8, we look separately at the effects of income inequality on the probabilities of completing at least one year of education, six years of education (corresponding to at least primary school completion), 10 years of education (at least lower secondary completion), 12 years of education (at least high school completion), and 15 years of education (college completion) respectively. The results are strongly supportive of the predictions of the marital search hypothesis: Whereas there is little evidence of an effect on the rates of completion of lower levels of education, rates of completion of high school and college increase significantly by 5.2 and 4.4 percentage points respectively.

[Table 8 here]

\section{Concluding discussion}

We use nationally representative data from India to test the hypothesis that increasing income inequality causes women to delay their marriage. In line with the predictions from a marital search model, we find that increases in upper tail inequality delay marriage, while increases in lower tail inequality have no significant effect. We examine a number of alternative hypotheses and conclude that the overall pattern of results strongly points towards the marital search mechanism. In particular, the results do not seem to be driven by an increased demand for higher education.

These results have an immediate welfare significance because the female age at marriage is thought to affect a host of economic and health outcomes. For example, early marriage has been associated with low contraceptive use, miscarriages, multiple unwanted pregnancies, domestic violence, depression, and even increased HIV risk (Bruce, 2003; 
Clark, 2004; Nour, 2006; Raj et al., 2009; Santhya et al., 2010). Although the exact mechanisms by which age at marriage affects later outcomes have not been definitively established in the literature, we focus on educational attainment, which is thought to be an important intermediate outcome, and show that women in high-inequality markets obtain more education. Consistent with the search hypothesis, higher income inequality increases high school and college completion rates by about 5.2 and 4.4 percentage points, but has no effect on rates of completion of lower levels of schooling. 


\section{References}

[1] Angrist, J. 2002. "How do sex ratios affect marriage and labor markets? Evidence from America's second generation," Quarterly Journal of Economics 117, 997-1038.

[2] Angrist, Joshua and J-S Pischke. 2009. Mostly Harmless Econometrics. Princeton University Press.

[3] Attane I. The Demographic Impact of a Female Deficit in China, 2000-2050. Population and Development Review. 2006;32:755-70.

[4] Atkinson, Anthony B. and Thomas Piketty (2010). Top Incomes over the Twentieth Century: A Global Perspective. (Volume 2) Oxford: University Press.

[5] Atkinson, Anthony B., Thomas Piketty and Emmanuel Saez, 2011. “Top Incomes in the Long Run of History."Journal of Economic Literature 49, no. 1: 3-71.

[6] Banerjee, Abhijit, and Thomas Piketty. 2005. “Top Indian Incomes, 1922-2000.”The World Bank Economic Review 19, no. 1: 1-20.

[7] Banerjee, A., E. Duflo, M. Ghatak and J. LaFortune. 2013. "Marry for What? Caste and Mate Selection in Modern India." American Economic Journal: Microeconomics, 5(2):33-72.

[8] Becker, G., E. Landes and R. Michael. 1977. "An Economic Analysis of Marital Instability," Journal of Political Economy, 25(6): 1141-88.

[9] Becker, Gary S., Kevin M. Murphy, and Robert Tamura. 1990. "Human capital, fertility, and economic growth," Journal of Political Economy 98, 12-37

[10] Bergstrom, T., and M. Bagnoli. 1993. "Courtship as a Waiting Game," Journal of Political Economy, 101(1): 185-202. 
[11] Blanchflower, D. and A. Oswald. 2003. "Does Inequality Reduce Happiness? Evidence from the States of the USA from the 1970s to the 1990s." Unpublished manuscript

[12] Boulier, B., and M. Rosenzweig. 1984. "Schooling, Search, and Spouse Selection: Testing the Economic Theories of Marriage and Household Behavior," Journal of Political Economy, 92(4): 712-32.

[13] Brien, Michael J., and Lee A. Lillard. 1994. “Education, Marriage, and First Conception in Malaysia."Journal of Human Resources 29, no. 4: 1167-1204.

[14] Bruce, Judith. 2003. "Married Adolescent Girls: Human Rights, Health, and Developmental Needs of a Neglected Majority."Economic and Political Weekly, October 11: $4378-4380$.

[15] Burdett, K. and J. Ondrich. "How Changes in Labor Demand Affect Unemployed Workers," Journal of Labor Economics, 3 (January): 1-10.

[16] Caldwell, J.C., Reddy, P.H. \& Caldwell, P. 1983. “Causes of Marriage Change in South India." Population Studies 37(3), 343-361

[17] Choe, Kim, Sidney B. Westley, and Robert D. Rutherford. 2002. "Tradition and Change in Marriage and Family Life". In: The Future of Population in Asia. Honolulu, HI: East-West Center.

[18] Clark, Shelley. 2004. "Early Marriage and HIV Risks in Sub-Saharan Africa."Studies in family planning 35 , no. 3: 149-160.

[19] Deaton, Angus, and Jean Dreze. 2002. "Poverty and Inequality in India: a ReExamination."Economic and Political Weekly, September 7: 3729-3748.

[20] Deaton, Angus, and Valerie Kozel. 2005. “Data and Dogma: The Great Indian poverty Debate."The World Bank Research Observer 20, no. 2: 177-199. 
[21] Field, Erica, and Attila Ambrus. 2008. "Early Marriage, Age of Menarche, and Female Schooling Attainment in Bangladesh."Journal of Political Economy 116, no. 5: 881-930.

[22] Freedman, R., P. Whelpton, and A. Campbell. 1959. Family Planning, Sterility, and Population Growth. New York:McGraw-Hill.

[23] Harwood-Lejeune, Audrey. 2001. "Rising age at Marriage and Fertility in Southern and Eastern Africa." European Journal of Population/Revue Européenne de Démographie 17, no. 3: 261-280.

[24] Jensen, Robert, and Rebecca Thornton. 2003. “Early Female Marriage in the Developing World."Gender \& Development 11, no. 2: 9-19.

[25] Kondo, N., G. Sembajwe, I. Kawachi, R. M. van Dam, S. V. Subramanian, and Z. Yamagata. 2009. "Income inequality, mortality, and self rated health: meta-analysis of multilevel studies," British Medical Journal, 339.

[26] Leigh, Andrew (2009). "Top Incomes", in W. Salverda, B. Nolan, and T. Smeeding (eds.) The Oxford Handbook of Economic Inequality. Oxford: Oxford University Press.

[27] Lichter Daniel T, McLaughlin Diane K, Kephart George, Landry David J. (1992). "Race and the Retreat from Marriage: A Shortage of Marriageable Men?" American Sociological Review. 1992;57(6):781-99.

[28] Lindstrom, David P., and Carlos Brambila Paz. 2001. "Alternative Theories of The Relationship of Schooling and Work to Family Formation: Evidence from Mexico."Biodemography and Social Biology 48, no. 3-4: 278-297.

[29] Loughran, David S. 2000. “Does Variance Matter? The Effect of Rising Male Wage Inequality on Female age at First Marriage." RAND Working Paper. 
[30] Loughran, David S. 2002. "The Effect of Male Wage Inequality on Female Age at First Marriage." Review of Economics and Statistics 84, no. 2: 237-250.

[31] Maertens, Annemie. 2013. "Social Norms and Aspirations: Age of Marriage and Education in Rural India." World Development 47. No.C : 1-15.

[32] McCall, John J. 1970. “Economics of Information and Job Search.” Quarterly Journal of Economics 84, no.1: 113-126.

[33] Mensch, Barbara S., Susheela Singh and John B. Casterline. 2005. "Trends in the Timing of First Marriage among Men and Women in the Developing World," in Cynthia B. Lloyd, Jere R. Behrman, Nelly P. Stromquist, and Barney Cohen (eds.), The Changing Transitions to Adulthood in Developing Countries: Selected Studies, Washington, DC: National Academies Press, 118-171.

[34] Mortensen, Dale T. 1986. "Job Search and Labor Market Analysis," in Handbook of Labor Economics. O. Ashenfelter and R. Layard, eds. Amsterdam: North Holland, 849-920.

[35] Nour, Nawal M. 2006. "Health Consequences of Child marriage in Africa."Emerging infectious diseases 12, no. 11: 1644-1649.

[36] Parthapratim Pal and Jayati Ghosh. 2007. "Inequality in India: A Survey of Recent Trends." Working Papers 45, United Nations, Department of Economics and Social Affairs.

[37] Piketty, T. 2006. "The Kuznets Curve: Yesterday and Tomorrow," in Understanding Poverty, edited by A. Banerjee, R. Benabou and D. Mookherjee.

[38] Piketty, T., and N. Qian. 2009. "Income Inequality and Progressive Income Taxation in China and India, 1986-2015." American Economic Journal: Applied Economics, 1(2): 53-63 
[39] Raj, Anita, Niranjan Saggurti, Donta Balaiah, and Jay G. Silverman. 2009. “Prevalence of Child Marriage and its Effect on Fertility and Fertility-Control Outcomes of Young Women in India: a Cross-Sectional, Observational Study."The Lancet 373, no. 9678: 1883-1889.

[40] Rao, V. 1993. "The Rising Price of Husbands: A Hedonic Analysis of Dowry Increases in Rural India," Journal of Political Economy, 101(4), pp. 666-677

[41] Rashad, Hoda and Osman, Magued. 2003. "Nuptiality in Arab countries: Changes and implications."In Nicholas Hopkins (eds) The New Arab Family. Cairo: The American University in Cairo Press: 20-50.

[42] Rios-Rull, J., Shannon Seitz, Satoshi Tanaka. 2013. "Sex-ratios and long-term marriage trends," Mimeo.

[43] Santhya, K. G., Usha Ram, Rajib Acharya, Shireen J. Jejeebhoy, Faujdar Ram, and Abhishek Singh. 2010. “Associations between Early marriage and Young Women's Marital and Reproductive Health Outcomes: Evidence from India."International Perspectives on Sexual \& Reproductive Health 36, no. 3: 132-139.

[44] Schoen, Robert. 1983. "Measuring the Tightness of a Marriage Squeeze," Demography, XX, 61-78.

[45] Srinivas, M. N. 1984. Some Reflections on Dowry. New Delhi: Oxford University Press.

[46] Sundaram, Krishnamurty, and Suresh D. Tendulkar. 2003A. "Poverty in India in the 1990s: Revised results for all-India and 15 major states for 1993-94."Economic and Political Weekly, December 13-19: 4865-4872. 
[47] Sundaram, Krishnamurty, and Suresh D. Tendulkar. 2003B. "Poverty in India in the 1990s: An Analysis of Changes in 15 Major States." Economic and Political Weekly, April 5: 1385-1393.

[48] Westoff, C. F., and R. H. Potvin. 1966. "Higher education, religion, and women's family size orientations." American Sociological Review 31 (August):489-496

[49] Westoff, Charles F. 2003. Trends in Marriage and Early Childbearing in Developing Countries. DHS Comparative Reports No. 5. Calverton, Maryland: ORC Macro. 